\title{
Effects of maternal deprivation on the somatotrophic axis and neuropeptide $Y$ in the hypothalamus and pituitary in female lambs. The histomorphometric study
}

\author{
Jolanta Polkowska, Marta Wańkowska \\ Department of Endocrinology, The Kielanowski Institute of Animal Physiology and Nutrition, Polish \\ Academy of Sciences
}

\begin{abstract}
The effects of maternal deprivation on the somatotrophic axis and neuropeptide Y (NPY) neuronal system in the hypothalamus of female lambs were evaluated. Twelve-week-old lambs were divided into two groups: the control (lambs stayed with mothers) and maternally deprived (MD; lambs separated for 3 days from mothers). The expression of immunoreactive (ir) somatostatin in the neurons of the periventricular nucleus (PEV) and in nerve terminals of the median eminence (ME), growth hormone (GH) in the adenohypophyseal cells and NPY in the neurons of the PEV and arcuate (ARC) nuclei of the hypothalamus using immunohistochemistry followed by the image analysis were estimated. Concentrations of $\mathrm{GH}$ in the blood plasma were determined by radioimmunoassay. The expression of ir somatostatin in the PEV and ME, ir NPY in the ARC and PEV, ir GH in adenohypophyseal cells, and blood plasma GH concentrations were greater $(\mathrm{p}<0.05)$ in MD than in the control lambs. In conclusion, MD affects the somatotrophic axis by enhancement of GH secretion via restraining of somatostatin output. The simultaneous increase of expression of hypothalamic ir NPY suggests NPY involvement in the regulation of psychoemotional stress through the somatotrophic axis in the female lambs.
\end{abstract}

Key words: maternal separation, somatostatin, growth hormone, neuropeptide Y, immunohistochemistry, sheep

\section{Introduction}

A separation from the mother is known to be a psychoemotional stress which induces some disturbances in behavioural and neuroendocrine mechanisms of adaptation [1]. Such separation determines lasting behavior and alters hypothalamic-pituitary-adrenal (HPA). axis responses in rats [2-4] and monkeys [5]. In farm animals, information concerning physiological consequences of disrupting mother-infant interactions especially with respect to endocrine functions are limited. In neonatal piglets, the repeated separation from mothers increases basal adrenocorticotrophin (ACTH) and cortisol concentration [6] In sheep under natural conditions, the rupture of the social connection may have long-term consequences, therefore, the weaning imposed by breeders may result in psychobiological disturbances. Separation of lambs from mothers causes behavioral

Correspondence: M. Wańkowska, Dept. of Endocrinology, The Kielanowski Institute of Animal Physiology and Nutrition, Polish Academy of Sciences, Instytucka 3 Str., 05-110 Jabłonna, Poland; tel.: (+4822) 7653315, fax.: (+4822) 7653302, e-mail: m.wankowska@ifzz.pan.pl alterations, some hormonal and immune changes and reduced growth $[7,8]$. Our recent data have shown that a disruption of preweanling lambs-mother social contact enhanced the release of corticotrophin releasing hormone $(\mathrm{CRH})$ from the median eminence (ME) and attenuates processing and release of ACTH [9]. However, the lamb's endocrine responses to stress have not been limited to the activation of the HPA axis but have also engaged other hypothalamic and pituitary hormones, especially the pituitary gonadotrophic hormones secretory activity [9] To continue our previous study we designed this experiment to determine the effect of maternal deprivation (MD) on the lamb's somatotrophic axis which is associated with growth and development, since the influence of stress caused by maternal deprivation on the somatotrophic axis has not been investigated in detail. In adult sheep such effects are mediated by an augmented input of endogenous somatostatin [10] and/or by possible action of growth hormone releasing hormone [11]. In adult anestrous ewes responses of hormones of the somatotrophic axis to stress caused by intermittent electric foot shocks strongly depend on the length of time during which the stressor is applied, and 
prolonged but not acute stimulation affects somatostatin neuronal system [12]. In rats, exposure to stressful stimuli affects the somatotrophic axis by decreasing of $\mathrm{GH}$ secretion [13].

One of the candidates for regulation of somatostatin in the rat and human hypothalamus is neuropeptide $\mathrm{Y}$, which represents a critical and central component of energy homeostasis, and influences the entire extent of the metabolic axis [14]. NPY is released into the peripheral circulation during psychological stress together with catecholamines involving neuroendocrine stress responses [15]. NPY is also a regulator of secretion of the anterior pituitary hormones such as GH, prolactin, LH [16]. Anatomically, NPY terminals are in close proximity with the somatostatin perikarya in the periventricular nucleus in sheep [17-19]. In sheep, the role of NPY in regulation of somatostatin was investigated only in the conditions of food deprivation and indicated that, nutritionally dependent decreasing release of somatostatin could be mediated by this hypothalamic peptide [18]. For rats, it has been demonstrated that NPY suppress GH release by stimulating somatostatin release [16].

The aim of the presented study was to test the hypothesis that acute isolation of lambs from their mothers in the period of weaning can affect the secretory activity of the somatotrophic axis and that NPY may be involved in this process. The effect of MD on the somatostatin and NPY neuronal systems in the hypothalamus, GH in the adenohypophyseal somatotrophic cells population and GH concentrations in the peripheral blood were investigated in weanling lambs using immunohistological and radioimmunological methods.

\section{Materials and methods}

Animals. The experiment was performed on Polish Merino female lambs born at the beginning of July at the Bieganowo Farm (Poland, $52^{\circ} \mathrm{N}$ and $\left.21^{\circ} \mathrm{E}\right)$. Lambs were left to graze with dams in a pasture for 12 weeks after parturition. Twelve-week-old lambs were divided randomly into either the control group $(n=3$; average weight $18.5 \pm 0.71 \mathrm{~kg}$ ) or maternally deprived group (MD group, $\mathrm{n}=3$; average weight $18.5 \pm 1.50 \mathrm{~kg}$ ).Control lambs grazed with dams on the pasture and suckled their mothers one to two times per $24 \mathrm{~h}$. MD group was separated from dams and was in partial isolation from the herd, and it was kept within the fenced part of the pasture (approximately $600 \mathrm{~m}^{2}$ ) for a period of $72 \mathrm{~h}$. Before tissue collection, MD lambs had direct contact among themselves and an inspected visual and olfactory contact with their herd (staying beyond the fence on the same pasture), but not with their dams. They grazed pasture and additionally were weaned to solid food and were allowed free access to water. Then, animals were subjected to an 8 min loading and a 5 min transportation (approximately $1 \mathrm{~km}$ in a livestock trailer with internal floor dimension of $3.5 \mathrm{~m} \times 2 \mathrm{~m}$ ) to a local licensed slaughterhouse. Immediately after unloading, a blood sample was taken by jugular venipuncture from each lamb. Lambs were anesthetized with an i.v. injection of pentobarbitone sodium $(20 \mathrm{mg} / \mathrm{kg}$; Biochemie $\mathrm{GmbH}$, Kundl, Austria) and slaughtered by decapitation at $73 \mathrm{~h} / 74 \mathrm{~h}$ after beginning of the experiment.
Tissue preparation and immunohistochemistry. Immediately after decapitation, brains were perfused via both carotid arteries with $1000 \mathrm{ml} 0.1 \mathrm{M}$ phosphate buffered saline (PBS; Sigma, St. Louis, USA) and subsequently with $1500 \mathrm{ml} 0.1 \mathrm{M}$ PBS containing $4 \%(\mathrm{w} / \mathrm{v})$ paraformaldehyde (Sigma-Aldrich, Germany) solution $(\mathrm{w} / \mathrm{v}), \mathrm{pH}$ 7.4. The hypothalami and pituitaries were dissected $20 \mathrm{~min}$ after the beginning of perfusion, postfixed for $72 \mathrm{~h}$ by immersion in the same fixative and washed with $0.01 \mathrm{M}$ PBS. Hypothalami jointly with the ME and pituitary stalk were cryoprotected in a $20 \%$ sucrose solution in $0.01 \mathrm{M}$ PBS for at least two days at $4^{\circ} \mathrm{C}$. Hypothalami were frozen at $-10^{\circ} \mathrm{C}$ and sectioned in frontal planes into $10 \mu \mathrm{m}$ sections on a cryostat (Jung CM 1500, Leica Instruments GmbH, Nussloch, Germany). Pituitaries were dehydrated in graded alcohols, embedded in paraplast (Sigma, St Louis, USA) and then $4 \mu \mathrm{m}$ sections were cut in the sagittal plane.

The immunoreaction for somatostatin, NPY and GH was developed by immunohistochemical technique. Hypothalami sections were washed in $0.1 \mathrm{M}$ PBS, incubated for $4 \mathrm{~h}$ in $1 \%$ hydrogen peroxide (Chempur, Piekary Ślaskie, Poland) in 0.1 M PBS and $24 \mathrm{~h}$ in $3 \%$ pre-immune normal lamb serum in $0.1 \mathrm{M}$ PBS. Pituitary sections were deparafined, rehydrated, washed in 0.01 PBS, incubated for $30 \mathrm{~min}$ in $2 \%$ pre-immune normal lamb serum in $0.01 \mathrm{M}$ PBS and $30 \mathrm{~min}$ in $0.1 \%$ hydrogen peroxide in $0.01 \mathrm{M}$ PBS. Hypothalami sections were incubated with primary antisera raised in the rabbit: anti-somatostatin, ref. 64714 (ICN, Biomedicals, Aurora, USA) diluted 1:2000 and anti-NPY, ref. 9528, (Sigma St Louis, USA) diluted 1:4000 for 6 days at $4^{\circ} \mathrm{C}$. Hypophyseal sections were incubated with primary rabbit anti-hGH antiserum ref 19538 diluted 1:800 for $48 \mathrm{~h}$ at $4^{\circ} \mathrm{C}$. Methodological details of its preparation and specificity are described by Dubois [20]. After incubation with primary antibodies, sections were rinsed in PBS and incubated for $2 \mathrm{~h}$ at room temperature $\left(\sim 20^{\circ} \mathrm{C}\right)$ with the secondary antibody (sheep anti-rabbit $\mathrm{Ig}[\mathrm{H}+\mathrm{L}]$ labelled with peroxidase (Bio-Rad, Steenvoorde, France), diluted 1:40 in $0.1 \%$ normal lamb serum in PBS. The colour reaction was developed by incubating sections with $0.05 \%$ 3'3-diaminobenzidine tetrachloride chromogen (DAB, Sigma, St Louis, USA) and $0.001 \%$ hydrogen peroxide in $0.05 \mathrm{M}$ Tris buffer. Hypothalami sections were additionally stained by the intensification method of Liposits et al. [21].

In the control staining, the primary antiserum was replaced with the same dilution of rabbit serum. To evaluate the specificity of staining, the inhibition of anti-hormone serum with its homologous antigen was used. The preincubation of somatostatin antiserum with $10 \mu \mathrm{g} / \mathrm{ml}$ synthetic somatostatin (cyclic Clin-Midy, France), NPY antiserum with $10 \mu \mathrm{g} / \mathrm{ml}$. synthetic NPY (ref. 6269, Sigma, St Louis, USA) and GH antiserum with $4 \mu \mathrm{g} / \mathrm{ml}$ with hGH (Sigma, St Louis, USA) for $24 \mathrm{~h}$ at $4^{\circ} \mathrm{C}$ used for immunohistochemical staining instead of the primary antibody blocked the immunostaining. Neither of the controls exhibited any specific staining (data not shown).

Radioimmunological analysis (RIA) of GH. Plasma GH concentration was estimated in duplicate by double-antibody RIA according to Slaba et al. [22], using pituitary derived bGH purified by chromatography on SE- Sephadex C-50 in sodium acetate buffer for iodination and reference standards. The first antibody was produced in rabbits against pituitary-derived bGH NIDDK-GH-B$1003 \mathrm{~A}$. The assay detection limit was $0.034 \mathrm{ng}$ corresponding to $0.68 \mathrm{ng} / \mathrm{ml}$ plasma per sample. The intra-assay CV averaged $5.9 \%$. The data are presented as mean $\pm \mathrm{SD}$. The level of significance for differences between two groups was calculated using the MannWhitney U test. Significance was defined at the $p<0.05$ level.

Ethical issues. All procedures were approved by the $3^{\text {rd }}$ Local Ethics Committee in Warsaw, according to the Polish Law for the Care and Use of Animals (2 August 1997). 
Image analysis. A Nikon type 104 projection microscope (Nikon Corporation, Yokohama, Japan) was used for histological analyses of hypothalamic and pituitary sections. Staining was analysed using the "Lucia" image analysis computer system version $3.51 \mathrm{ab}$ (Laboratory Imaging Ltd, Prague, Czech Republic). Images of stained sections were projected by camera (Panasonic KR222, Matsushita Electric Industrial Co, Osaka, Japan) into a color monitor. Images were adjusted for optimal contrast, fixed at the same brightness levels, converted to grey and saved in a buffering system. Analyses were performed with a $20 \times$ objective lens for NPY and somatostatin perikarya, $4 \times$ for the somatostatin nerve terminals in the ME and $40 \times$ objective for adenohypophyseal GH cells. The area fraction, parameter defining the percentage of the total area that exhibited specific staining was measured. This parameter expresses the population of positively stained cross-sections of perikarya, fibers, nerve terminals in the ME or adenohypophyseal cells. Quantitative analyses were performed for each hypothalamus in the sub-area of interest using a threshold function to select a range of grey values identified as positive staining. All other values were referred to as non-staining. The threshold value was different for pituitary, both hypothalamic nuclei, the ME and individual hormones and constant for all measured pictures of one histochemical product. The frame size was kept constant for the duration of the image analysis. Before measurements, the images were processed by subtracting the background and removing all artifacts. Analyses of percentage area for the immunoproduct in the ir somatostatin nerve terminals were estimated in the delineated area containing the middle part of the ME. Measurements were performed on every fourth section ( 24 sections per animal) for the total area of $100 \mathrm{~mm} 2$ for each hypothalamus. Immunoproducts in the somatostatin and/or NPY were analysed on both sides of the third ventricle in the periventricular (PEV) nucleus and on both sides of the recessus infundibularis in the $\mathrm{ARC}$ and paraventricular (PVN) nuclei. The quantification of data obtained for the immunoproduct was based on $\sim 24$ measurements in 12 sections for each nucleus in the sub-area of interest $\left(0.2293 \mathrm{~mm}^{2} /\right.$ field $)$. The analyses of the immunoreaction in adenohypophyseal GHcells were made in four sections of pars distalis of each pituitary gland using every $40^{\text {th }}$ serial section (16 fields each of 0.0837 $\mathrm{mm}^{2}$ were measured per section).

Statistical analysis. The data from each section were averaged to obtain a mean, estimated for each nucleus, each ME or adenohypophysis within each animal. Then, the mean data were pooled to represent the control or experimental group. For the small sample size $(n=3)$, to compare groups the data were analyzed using the Mann-Whitney U test, the non-parametric equivalent of Student's t-test for non-linked samples using the Statistica 6.0 PL software system (StatSoft, Inc., Tulsa, OK, USA). The data are reported as mean of percentage \pm SEM of the total area that exhibited positive and specific immunostaining. Significance was defined at the $\mathrm{p}<0.05$ level.

\section{Results}

\section{Immunoreactivity of somatostatin in hypothalamus}

In both groups, ir somatostatin perikarya were localized in the PEV nucleus. These perikarya extended from the suprachiasmatic area in the anterior hypothalamus to the paraventricular zone in the medial basal hypothalamus. Immunoreactive somatostatin nerve terminals in the ME were arranged in its external zone across the entire width of this organ showing greatest accumulation in the medial part.

Clear-cut differences in the number of ir perikarya, density of fibers and nerve terminals were seen between the two groups (Fig. 1). In control lambs a very weak immunostaining of somatostatin in a few visible cells was observed. In contrast, in MD lambs, the PEV center displayed a moderate number of cells and fibers filled with ir somatostatin (Fig. 1 A-B). The image analysis demonstrated, that the percentage of the area exhibiting positive staining was greater $(\mathrm{p}<0.05)$ in the MD group, compared to the control group (Fig. 2A).

The ir somatostatin terminals in the ME were optically more abundant in the MD group than in the control group (Fig. 1C-D). This was reflected by the significantly $(p<0.05)$ greater percentage of the area occupied by ir somatostatin nerve terminals in the $\mathrm{ME}$ of the MD group compared to the control group (Fig. 2A).

\section{Immunoreactivity of $\mathrm{GH}$ cells in pituitary and GH concentration in peripheral blood}

The population of adenohypophyseal cells stained positively for GH was greater in MD lambs than in controls, but intensity of staining was low in the majority of these cells (Fig. 1E-F). The image analysis demonstrated that the area exhibiting positive staining was greater $(\mathrm{p}<0.05)$ in the MD group compared to the control group (Fig. 2A).

The mean GH concentration in the blood plasma of the MD group of lambs was significantly $(\mathrm{p}<0.05)$ higher than in the control group $(9.03 \pm 1.41 \mathrm{vs}$. $6.64 \pm 0.91 \mathrm{ng} / \mathrm{ml})$.

\section{Immunoreactivity of NPY in hypothalamus}

In both groups, the ir NPY neurons were localized typically in three distinct sub-areas of the hypothalamus. In the PEV nucleus and in the periventricular subdivision of the PVN nucleus only the nerve fibers were localized. Immunoreactive NPY perikarya were seen only in the ARC nucleus. In the control group, the expression of ir NPY fibers and perikarya was very weak in PEV and ARC nuclei (Fig. 3 A-C) with relatively high expression of ir NPY fibers in the PVN nucleus. Contrary, in the MD group a prominent expression of varicose ir NPY fibers in the PEV nucleus and considerable number of NPY perikarya in the ARC nucleus appeared (Fig. 3 B-D). No changes in NPY expression were observed in the PVN nucleus. Percent area exhibited positive NPY staining in PEV and ARC but not in PVN hypothalamic nuclei was greater $(\mathrm{p}<0.05)$ in the MD group compared to the control group (Fig. 2 B). 

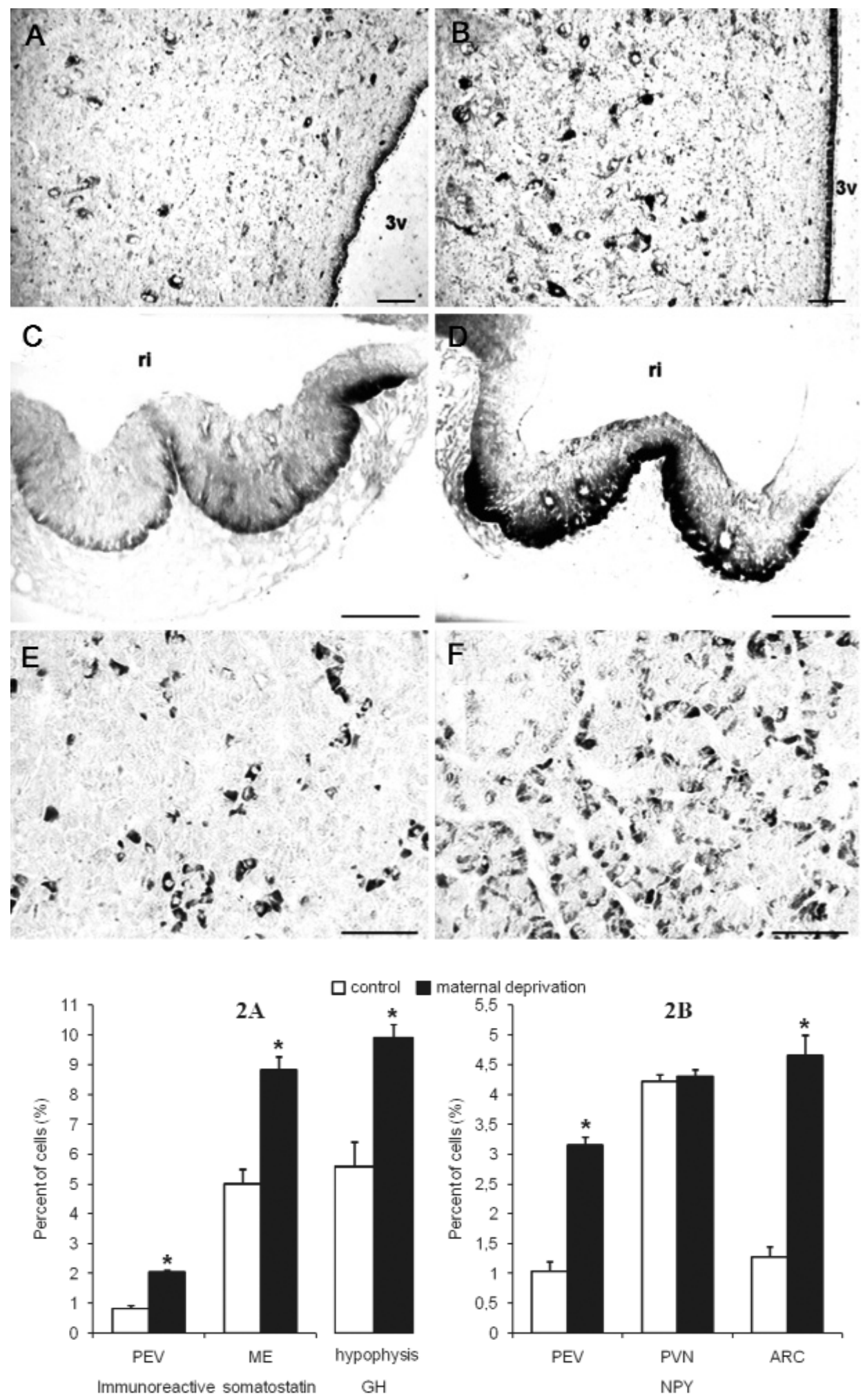

Fig. 1. Population of immunoreactive (ir) somatostatin perikarya and fibers in the periventricular nucleus (A and B), ir somatostatin terminals in the median eminence ( $\mathbf{C}$ and D), and ir growth hormone (GH) cells in the adenohypophyses ( $\mathbf{E}$ and $\mathbf{F}$ ) of representative lambs from the control group (left panel) and maternally deprived groups (right panel). ri, recessus infundibularis; $3 \mathrm{v}$, third ventricle of the brain; scale bars: A, B, E, F = $50 \mu \mathrm{m} ; \mathrm{C}, \mathrm{D}=500 \mu \mathrm{m}$.

Fig. 2. The percentage for the nerve elements expressing immunoreactivity for somatostatin in the periventricular nucleus and the median eminence and for the cells expressing immunoreactivity of $\mathrm{GH}$ in the adenohypophyses of lambs from the control and maternally deprived groups (A). The percentage for the nerve elements expressing immunoreactivity for neuropeptide Y (NPY) in the periventricular, paraventricular and arcuate nucleus of lambs from the control and maternally deprived group (B). ${ }^{*}$ p $<0.05$; means \pm S.E.M.

\section{Discussion}

\section{Somatostatin and growth hormone}

The present study demonstrates that the stressful experience of maternal deprivation affects the immunoreactivity of somatostatin in the hypothalamus, GH expression in the pituitary gland and GH concentration in blood plasma. Overall, histomorphological and hormonal evaluations indicate that MD causes the inhibition of somatostatin release and enhancement of GH release to the circulating blood in female lambs. The microscopic observations of the hypothalamus show 


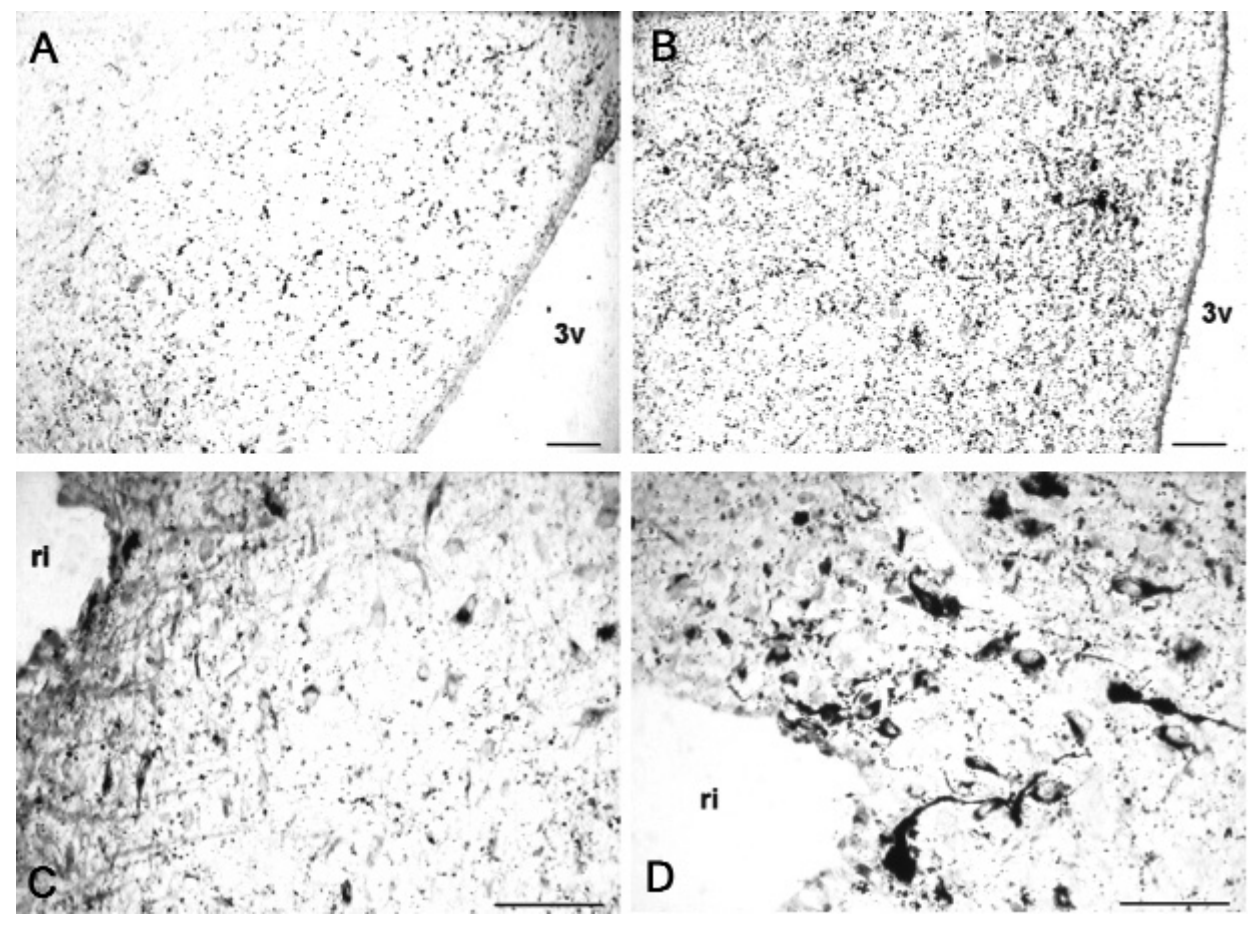

Fig. 3. Population of immunoreactive (ir) neuropeptide Y (NPY) fibers in the periventricular nucleus (A and $\mathbf{B})$ and ir NPY perikarya and fibers in the arcuate nucleus $(\mathbf{C}$ and D) of representative lambs from the control group (left panel) and maternally deprived group (right panel). $3 \mathrm{v}$, third ventricle of the brain; ri, recessus infundibularis; scale bars $=50 \mu \mathrm{m}$. that MD intensifies the immunoreaction in the cells forming the somatostatin perikaryonal centre and augments somatostatin stores in the nerve terminals of the ME. This can be interpreted as a restriction of the somatostatin transport as well as release rather than augmentation of its synthesis. In the sheep, the effect of MD on the somatotrophic axis has not been previously investigated. In maternally deprived rat pups, somatostatin content measured in the hypothalamic tissue increased [11]. The authors suggested, that such modifications might be related to suppression of GH. that was known to result from MD in this species. Thus, these data demonstrated that synthesis of the somatostatin increased in these experimental conditions. However, it is unclear if a peptide is released to the portal circulation. Therefore, this subject requires additional investigation.

The disorders in the somatotrophic axis due to stressful stimulation can be associated with enhanced activation of $\mathrm{CRH}$. In rats exposed to stress, $\mathrm{CRH}$ stimulates in vitro hypothalamic somatostatin release $[23,24]$ and inhibits GH secretion [10]. Moreover, the action of central $\mathrm{CRH}$ in the regulation of GH secretion in rats is mediated by the stimulation of hypothalamic somatostatin [25]. In contrast to rats, where both acute and prolonged stressful stimulation suppress the GH secretion mediated by somatostatin [26], various stressful stimuli elicit an increase of circulating GH in monkeys and humans [27,28]. For ruminants, data concerning the relation between stress and the somatotrophic axis are very limited and sometimes contradictory, since results depend strongly on the nature and duration of the stressful stimuli. In infantile lambs, the prolonged exposure to MD increases the release of $\mathrm{CRH}$ from the ME [9]. Short isolation-restraint stress involved rapid release of GH in male sheep [29]. In females, only prolonged but not short footshocking induced rapid release of somatostatin from the nerve terminals of the median eminence [30]. It was suggested that stimulation of GH pulsatility caused by acute stress could be mediated rather by GHRH but not somatostatin in sheep [29]. However, the mechanism of action of CRH and/or stressful stimulation on the somatotrophic axis in sheep has not been fully elucidated. The presented results give an additional evidence that somatostatin can take part in the psychoemotional stress-related mechanism in sheep.

In the current study, MD resulted also in the increase of activity of somatotrophic pituitary cells. This was manifested by enhancement of the number of these cells, GH expression and GH release reflected by the rise in the plasma concentration. There are some evidences about the inhibitory effects of MD on GH in rats [31,32], and stimulatory effects in the macaque [5]. Present results suggest some stimulation of somatotrophic pituitary cells activity which resulted in an increasing release of $\mathrm{GH}$ to the portal circulation in MD lambs.

In summary, MD affects the somatotrophic axis in female lambs by diminishing somatostatin release from the nerve terminals of the ME. This corresponds well with the increased secretory activity of the pituitary growth hormone-producing cells and an increase in the GH concentration in the blood plasma. 


\section{Neuropeptide $Y$}

The present results demonstrated that MD caused an increase of population of NPY neurons in the ARC nucleus. In fact, the ARC nucleus is known to be a principle site of NPY synthesis in the hypothalamus [33]. However in the sheep, immunoreactivity of NPY perikarya can be observed rather in very specific conditions like after colchicine treatment [33], in some physiological conditions related to starvation /long term malnutrition [19], or the preovulatory phase of the oestrous cycle [34]. It has been suggested that a visualization of perikarya in the sheep may result from their enhanced secretory activity in the hypothalamus [33]. Changes in the activity of ARC NPY in conditions of MD were seen in rat pups. The 24-36 h separation from the mother increased expression of mRNA NPY in the ARC nucleus $[35,36]$. Also the restraint stress increased NPY mRNA in the ARC nucleus of the hypothalamus [37]. Increased activity of NPY perikarya in conditions of MD is likely due to their role in metabolic stress [38] and/or response to the stress of maternal separation [39]. However, in the MD lambs no changes were observed in the ir NPY in the PVN nucleus, which is responsible for both, the metabolic and stress mediation [reviewed in 39]. Similarly, in MD rats, unaffected NPY neurons in the PVN were observed [35]. According to Grove and Smith [40] the various populations of hypothalamic NPY neurons can respond in different ways to $\mathrm{MD}$, which can be related to the incomplete development of ARC projections in this ontogenic period.

In contrast to PVN nucleus, in the PEV nucleus a marked increase of population of ir NPY fibers has been observed in the present study. The periventricular area of the hypothalamus was established as the centre of the somatostatin synthesis in many species including sheep [reviewed in 30]. This suggests, that NPY terminals located in this area can be involved in the regulations associated with the somatotrophic axis. In fact, in our previous study we have demonstrated that nutritional manipulations augmented the activity of periventricular NPY-ir fibers with concomitant somatostatin output in sheep $[18,19]$. Immunohistochemical studies have demonstrated synaptic connections between NPY containing axons and somatostatin perikarya in the PEV nucleus of rats [41] and sheep [17]. Our last study on anatomical connections between NPY and somatostatin neurons demonstrated such links in prepubertal lambs on the levels of PEV and ARC nuclei (unpublished). The direct interactions between the somatostatin and NPY in the area of ARC nuclei were found in rats where approximately $7 \%$ of NPY perikarya coexpressed the specific receptor for somatostatin -sst1 [42].These data suggest that there is an anatomical basis for interactions between these two groups of cells and that NPY neurons can influence the secretion of GH by influencing hypothalamic somatostatin neurons.

In summary, the increasing activity of ir NPY neuronal population in the hypothalamus especially in the PEV nucleus, with concomitant decrease of somatostatin output from periventricular perikarya and from nerve terminals in the ME suggests, that NPY may play a role in the regulation of the somatotrophic axis in lambs separated from their mothers.

In conclusion, rupture of the young offspring-mother contact affects the somatotrophic axis by enhancement of GH secretion via restraining of somatostatin output. It is suggested that some subpopulation of the hypothalamic NPY neurons can be involved in the mechanism of regulation of psychoemotional stress through the somatotrophic axis in the female lambs.

\section{References}

[ 1] Kuhn CM, Schanberg SM. Responses to maternal separation: mechanisms and mediators. Int J Dev Neurosci. 1998;16:261270.

[2] Stanton ME, Gutierrez YR, Levine S. Maternal deprivation potentiates pituitary-adrenal responses in infant rats. Behav Neurosci. 1988;102:692-700.

[3] Suarez MM, Rivarola MA, Molina SM, Perassi NI, Levin GM, Cabrera R. Periodic maternal deprivation and lesion of anterodorsal thalami nuclei induce alteration on hypophysisadrenal system activity in adult rats. Life Sci. 2001;69:803813.

[ 4] Workel JO, Oitzl MS, Fluttert M, Lesscher H, Karssen A, de Kloet ER. Differential and age-dependent effects of maternal deprivation on the hypothalamic-pituitary-adrenal axis of brown Norway rats from youth to senescence. $J$ Neuroendocrinol. 2001;13:569-580.

[ 5] Laudenslager ML, Boccia ML, Berger CL, Gennaro-Ruggles MM, McFerran B, Reite ML. Total cortisol, free cortisol and growth hormone associated with brief social separation experiences in young macaques. Dev Psychobiol. 1995;28:199211.

[ 6] Kanitz E, Tuchscherer M, Puppe B, Tuchscherer A, Stabenow B. Consequences of repeated early isolation in domestic piglets (Sus scrofa) on their behavioural, neuroendocrine and immunological responses. Brain Behav Immunol. 2004; 18:35-45.

[7] Napolitano F, Annicchiarico G, Caroprese M, De Rosa G, Taibi L, Sevi A. Lambs prevented from suckling their mothers display behavioral, immune and endocrine disturbances. Physiol Behav. 2003;78:81-89.

[ 8] Orgeur P, Bernard S, Naciri M, Nowak R, Schaal B, Levy F. Psychobiological consequences of two different weaning methods in sheep. Reprod Nutr Dev. 1999;39:231-244.

[ 9] Wańkowska M, Starzec A, Counis R, Polkowska J. Effects of maternal deprivation on the adrenocorticotrophic and gonadotrophic axes in the hypothalamo-pituitary unit of preweanling female sheep: The histomorphometric approach. J Chem Neuroanat. 2006;31:51-58.

[10] Rivier C, Vale W. Involvement of corticotropin-releasing factor and somatostatin in stress-induced inhibition of growth hormone secretion in the rat. Endocrinology. 1985;117:24782482.

[11] Juarez LM, Meserve LA. Modifications of hypothalamic content of growth hormone regulatory peptides in maternally deprived neonatal rats. Growth Dev Aging. 1988;52:139-143. 
[12] Polkowska J, Przekop F. Immunocytochemical changes in hypothalamic and pituitary hormones after acute and prolonged stressful stimuli in the anestrous ewe. Acta Endocrinol (Copenh). 1988;118:269-276.

[13] Veldhuis JD, Roemmich JN, Richmond EJ, Bowers CY. Somatotropic and gonadotropic axes linkages in infancy, childhood, and the puberty-adult transition. Endocrine Rev. 2006;27:101-140.

[14] White JD. Neuropeptide Y: a central regulator of energy homeostasis. Reg Peptides. 1993;49:93-107.

[15] Mormede P, Castagne V, Rivet JM, Gaillard R, Corder E. Involvement of neuropeptide $\mathrm{Y}$ in neuroendocrine stress responses. Central and peripheral studies. J Neural Transm. 1999;Suppl 1:65-75.

[16] Rettori V, Milenkovic R, Aguila MC, Mc Cann SM. Physiologically significant effect of neuropeptide $\mathrm{Y}$ to suppress growth hormone release by stimulating somatostatin discharge. Endocrinology. 1990;126:2296-2301.

[17] Iqbal J, Manley TR, Ciofi P, Clarke IJ. Reduction in adiposity affects the extent of afferent projections to Growth Hormone-Releasing Hormone and somatostatin neurons and the degree of colocalization of neuropeptides in Growth Hormone-Releasing Hormone and somatostatin cells of the ovine hypothalamus. Endocrinology. 2005;146:4776-4785.

[18] Gładysz A, Krejči, P, Šimunek J, Polkowska J. Effects of central infusions of neuropeptide $\mathrm{Y}$ on the somatotropic axis in sheep fed on two levels of protein. Acta Neurobiol Exp. 2001;61:255-266.

[19] Polkowska J, Gładysz A. Effect of food manipulation on the neuropeptide $\mathrm{Y}$ neuronal system in the diencephalon of ewes. J Chem Neuroanat. 2001;21:149-151.

[20] Dubois MP. Mise en evidence par immuno-fluorescence des cellules somatotropes et des cellules a prolactine dans $1^{\prime}$ hypophyse foetale des bovins. $C R$ Acad Sc. (Paris). 1971;272:433-435.

[21] Liposits Z, Sétalo G, Flérko B. Application of the silver-gold intensified 3,3'-dianminobenzidine chromogen to the light and electron microscopic detection of the luteinizing hormone-releasing hormone system in the rat brain. Neuroscience. 1984;13:513-525.

[22] Slaba J, Krejči P, Škarda J, Huybrechts LM, Decuypere E, Herrmann H. Plasma profiles of somatotropin and IGF-I in dairy cows following application of two preparations of recombinant bovine somatotropin in a sustained release vehicle. Physiol Rev. 1994;43:37-43.

[23] Peterfreund RA, Vale WW. Ovine corticotropin-releasing factor stimulates somatostatin secretion from cultured brain cells. Endocrinology. 1983;112:1275-1278.

[24] Aguila MC, McCann SM. The influence of hGRF, CRF, TRH and LHRH on SRIF release from median eminence fragments. Brain Res. 1985;348:180-182.

[25] Katakami H, Arimura A, Frohman LA. Involvement of hypothalamic somatostatin in the suppression of growth hormone secretion by central corticotropin-releasing factor in conscious rats. Neuroendocrinology. 1985;41:390-393.

[26] Terry LC, Willoughby JO, Brazeau P, Martin JB, Patel Y. Antiserum to somatostatin prevents stress-induced inhibition of growth hormone secretion in the rat. Science. 1976;192:565-567.

[27] Brown GM, Schalch DS, Reichlin S. Patterns of growth hormone and cortisol responses to psychological stress in the squirrel monkey. Endocrinology. 1971;88:956-963.

[28] Schalch DS. The influence of physical stress and exercise on growth hormone and insulin secretion in man. J Lab Clin Med. 1967;69:256-262.

[29] Cataldi M, Magnan E, Guillaume V. Acute stress stimulates secretion of GHRH and somatostatin into hypophyseal portal blood of conscious sheep. Neurosci Lett. 1994;178:103-106.

[30] Polkowska J. Development of the gonadotrophic and somatotrophic axes of sheep. J Reprod Fertil (Suppl.) 1995;49: 187-195.

[31] Kuhn CM, Butler SR, Schanberg SM. Selective depression of serum growth hormone during maternal deprivation in rat pups. Science. 1978;201:1034-1036.

[32] Kuhn CM, Pauk J, Schanberg SM. Endocrine responses to mother-infant separation in developing rats. Dev Psychobiol. 1990;23:395-410.

[33] Chaillou E, Baumont R, Chilliard Y, Tillet Y. Several subpopulations of neuropeptide $\mathrm{Y}$-containing neurons exist in the infundibular nucleus of sheep: an immunohistochemical study of animals on different diets. J Comp Neurol. 2002;444:129-143.

[34] Polkowska J, Wańkowska M, Wójcik-Gładysz A. Expression of NPY-immunoreactive neurons in the hypothalamus of the cycling ewe. Folia Histochem Cytobiol. 2006;44:13-16.

[35] Grove KL, Allen S, Grayson BE, Smith MS. Postnatal development of the hypothalamic neuropeptide Y system. Neuroscience. 2003;116:393-406.

[36] Tong Y, Dumont Y, Shen SM, Quirion R. Comparative developmental profile of the neuropeptide Y Y1 receptor gene and protein in the rat brain. Mol Brain Res. 1997;48:323-332.

[37] Conrad CD, McEwen BS. Acute stress increases neuropeptide Y mRNA within the arcuate nucleus and hilus of the dentate gyrus. Brain Res Mol Brain Res. 2000;79:102-109.

[38] Kowalski TJ, Ster AM, Smith GP. Increased hypothalamic neuropeptide $\mathrm{Y}$ expression in deprived preweanling rats is reversed by ingastric infusion of milk. Physiol Behav. 2002;75:425-432.

[39] Smith MV, Liebl C, Sterlemann V. Neuropeptide Y mediates the initial hypothalamic-pituitary-adrenal response to maternal separation in the neonatal mouse. J Endocrinol. 2008;197:421-427.

[40] Grove KL, Smith MS. Ontogeny of the hypothalamic neuropeptide Y system. Physiol Behav. 2003;79:27-63.

[41] Hisano S, Tsumo Y, Kagotami Y, Daikoku S, Chihara K. Immunohistochemical evidence for synaptic connections between neuropeptide Y-containing axons and periventricular somatostatin neurons in the anterior hypothalamus in rats. Brain Res. 1990;520:170-177.

[42] Fodor M, Van Elk EJ, Huizinga CT, Delemarre-Van de Waal HA. NPY neurons express somatostatin receptor subtype 1 in the arcuate nucleus. Neuroreport. 2005;19:29-32.

Submitted: 5 November, 2009 Accepted after reviews: 29 March, 2010 